\title{
Polymer blends of poly(2-cyanoethyl vinyl ether) and poly(methyl methacrylate) with improved dielectric properties for flexible electronics
}

\author{
F. Piana*, J. Kredatusová, B. Paruzel, J. Pfleger \\ Institute of Macromolecular Chemistry, Academy of Sciences of the Czech Republic v.v.i., Heyrovsky Sq. 2, 16206 \\ Prague 6, Czech Republic
}

Received 7 February 2017; accepted in revised form 16 April 2017

\begin{abstract}
There is a big demand for the development of polymer materials for flexible electronics, among them polymers with a high dielectric constant play an important role. Here the preparation and properties of a polymer blend composed of poly(2-cyanoethyl vinyl ether) (CEPVA) as an amorphous polymer with dielectric constant $\left(\varepsilon^{\prime}\right) \sim 15$ but glass temperature $\left(T_{\mathrm{g}}\right)$ close to room temperature, and poly(methyl methacrylate) (PMMA), a polymer with low $\varepsilon^{\prime} \sim 5$ and high $T_{\mathrm{g}}$, are reported. The film forming ability, structure and dielectric properties of the blend are reported to verify its applicability for capacitors and field effect transistors. PMMA:CEPVA ratios 10:90 and 30:70 represent the best composition for obtaining a monophasic system with increased dielectric constant and $T_{\mathrm{g}}$ well above the room temperature. The improved properties have been attributed to the impact of PMMA on the relaxation phenomena of CEPVA, namely to an increased mobility of cyano-groups responsible for the dielectric behavior, as it was observed by the broadband dielectric and nuclear magnetic resonance (NMR) spectroscopies.
\end{abstract}

Keywords: polymer blends and alloys, dielectric properties, differential scanning calorimetry, scanning electron microscopy, NMR

\section{Introduction}

Polymers are key materials for the fabrication of innovative flexible printed electronics, where they can now substitute most of the inorganic components [1]. Conjugated polymers can be applied as electrodes if they are conductive, or as semiconductors in their undoped state [2]. Dielectric layers require insulating polymers with polarizable functional groups to increase their dielectric constant $\left(\varepsilon^{\prime}\right)$ [3]. In the preparation of dielectric layers for organic electronics by printing technology, a critical point is their thickness, which has to be sufficiently low in order to compensate low dielectric constant of traditional polymers [4]. On one side, the dielectric layer has to be thin enough to allow for a high capacitance of the device, which yields a sufficient accumulated charge already at low applied voltage [5] and allows for the threshold voltage in field effect transistors applicable in today's electronics [6]. On the other side, the dielectric layer has to be thick enough to avoid a current leakage or electrical breakdown.

Poly(2-cyanoethyl vinyl ether) (CEPVA) is an amorphous polymer obtained from poly(vinyl alcohol) (PVA) by substitution of hydroxyl groups with etheric bonded side chains containing $-\mathrm{C} \equiv \mathrm{N}$ groups. The cyano group possesses a strong permanent dipole, which leads to high values of the electrical permittivity $\left(\varepsilon^{\prime} \sim 15\right)$ [7]. Dielectric properties of this polymer and its composites have been investigated and results were found promising for application of this

${ }^{*}$ Corresponding author, e-mail: piana@imc.cas.cz

(C) BME-PT 
material as dielectrics in various electronic devices [8]. CEPVA has, however, a glass transition temperature $\left(T_{\mathrm{g}}\right)$ close to room temperature, which could create stability problems of the output current in OFETs or in the capacitors performance at usual ambient conditions [9]. At low applied frequency, in fact, $\varepsilon^{\prime}$ increases drastically at temperatures over $T_{\mathrm{g}}$ due to a rearrangement of polymer chains [7].

In this work we present a study focused on dielectric properties of polymer blends obtained by mixing CEPVA with various amount of poly(methyl methacrylate) (PMMA). PMMA has $\varepsilon^{\prime} \sim 5$ and $T_{\mathrm{g}}=110^{\circ} \mathrm{C}$ and it has been widely applied in dielectric layers as a pure polymer [10] or as a polymer composite in combination with various fillers like barium titanate [11], carbon nanotubes [12], etc. Moreover, it shows a good thermal stability, optical clarity and an excellent chemical resistance [13] For the concentrations lower than $30 \mathrm{wt} \%$ of PMMA in the blend, these two polymers were found to form a solution; at concentrations higher than $50 \mathrm{wt} \%$ phase separation has been observed. The resulting structure is strongly sensitive to the preparation protocol. The introduction of PMMA increases $\varepsilon^{\prime}$ values up to 27 at $10^{4} \mathrm{~Hz}$ with a simultaneous increase of $T_{\mathrm{g}}$, with a consequent improvement of the thermal stability of the electrical properties compared to the pure CEPVA polymer.

\section{Materials and methods}

\subsection{Materials}

Poly(methyl methacrylate), $M_{\mathrm{w}}=996000$, was obtained from Aldrich, poly(2-cyanoethyl vinyl ether) has been synthesized in the laboratories Joint Stock Co. Plastpolymer (St-Petersburg, Russia) via substitution of polyvinyl alcohol (PVA) by -CN groups, substitution level $80 \%$ (elemental analysis data of the provider). N,N-dimethylformamide $(99.8 \%)$ was purchased from Lachner, b.p. $153{ }^{\circ} \mathrm{C}(1013 \mathrm{hPa})$.

\subsection{Capacitors preparation}

The solutions for film casting were prepared by dissolving $100 \mathrm{mg}$ of a polymer mixture in $2 \mathrm{~mL}$ DMF. The weight ratios of PMMA and CEPVA were 0:100, 10:90, 30:70, 50:50, 70:30, 90:10 and 100:0, respectively. After filtering through Whatman PTFE filter, pore size $0.12 \mu \mathrm{m}$, the solutions were drop cast on electrolytically gold plated brass substrates preheated to $80^{\circ} \mathrm{C}$ and let dry first in air for $6 \mathrm{~h}$ and subsequently in vacuum at $40^{\circ} \mathrm{C}$ overnight. The films thickness varied between 10 to $30 \mu \mathrm{m}$. For the dielectric measurements top gold electrodes (diameter $5 \mathrm{~mm}$, thickness $70 \mathrm{~nm}$ ) were deposited on the upper surface of the layers by vacuum evaporation.

\subsection{Characterization methods}

Structural investigations were performed using Tescan Vega SB SEM (scanning electron microscope) after sputtering Ag on the top surface of the films using a Leica EM SCD050 sputtering device coupled with a crystal balance monitor Leica EM QSG100 (HV 30.0 kV, SE Detector). Dielectric properties have been evaluated by Broadband Dielectric Spectroscopy (BDS) in the frequency range $10^{-2}-10^{7} \mathrm{~Hz}$ using Novocontrol Alpha-A Analyzer at applied a.c. voltage $V_{\mathrm{rms}}=1.0 \mathrm{~V}$ in $\mathrm{N}_{2}$ atmosphere. The samples were measured under nitrogen first at $20^{\circ} \mathrm{C}$ and then in a cycle from -120 to $100^{\circ} \mathrm{C}$, isothermally with steps of $10^{\circ} \mathrm{C}$. Fourier transform infrared (FT-IR) spectra were acquired with Perkin Elmer Spectrum 100 spectrophotometer from polymer films surface. The thickness of the films was measured using KLA Tencor $\mathrm{P}-10$. Differential scanning calorimetry (DSC) analysis was carried out on a TA Instruments Q2000 calorimeter with $\mathrm{N}_{2}$ gas purge $\left(50 \mathrm{~cm}^{3} / \mathrm{min}\right)$. The instrument was calibrated for the temperature and heat flow using indium as a standard. Samples of about $5 \mathrm{mg}$ were encapsulated in T-zero aluminum pans. The analyses were performed in heating - cooling heating cycles from -80 to $200^{\circ} \mathrm{C}$ at a heating rate of $10^{\circ} \mathrm{C} / \mathrm{min} ; 5 \mathrm{~min}$ isothermal plateau was inserted before and between the ramps. ${ }^{1} \mathrm{H}$ spin-spin relaxation times $T_{2}$ measurements were acquired with Bruker Avance III 600 spectrometer operating at 600.2 MHz. Relaxation times $\tau$ were measured using the CPMG pulse sequence $90^{\circ} x$-(td- $180^{\circ} y$-td)n-acquisition [14]. The relaxation delay between scans was $100 \mathrm{~s}$, acquisition time $2.84 \mathrm{~s}$, single scan.

\section{Results and discussion}

The films cast on Au-plated brass electrodes were characterized with FT-IR spectroscopy to verify the interactions between the etheric and cyano groups of CEPVA and the methyl and ester groups of PMMA. The spectra of the blends are compared to the spectra of pure polymers in Figure 1. The FT-IR spectra of the blends show the absorption bands typical for the pure polymers proportionally to their fractions. The weak bands between 2850 and $3000 \mathrm{~cm}^{-1}$ show the $\mathrm{C}-\mathrm{H}$ bonds stretching vibrations; the band at $3000 \mathrm{~cm}^{-1}$ corresponds to the methyl groups of 


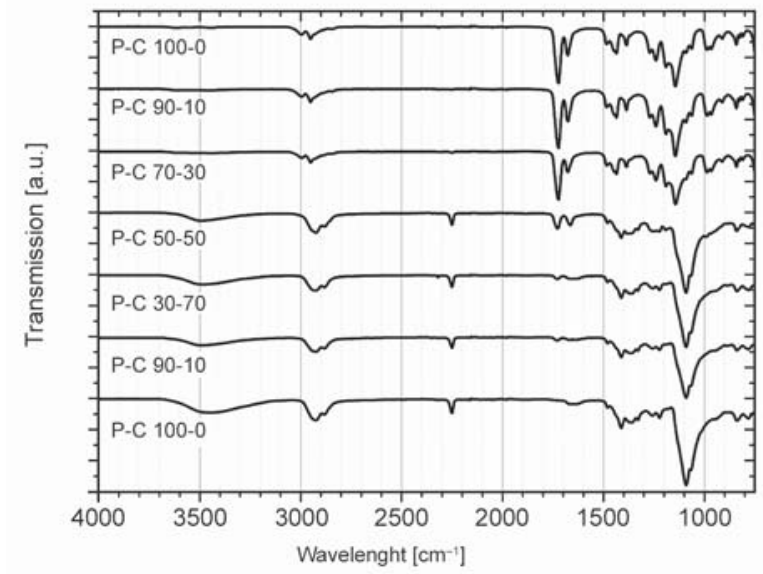

Figure 1. FT-IR performed on CEPVA-PMMA polymer blend films with different polymers concentrations (Concentrations shown in the legend.)

PMMA. For the higher concentrations from above $30 \mathrm{wt} \%$ of CEPVA the vibrations involving its secondary and tertiary carbon atoms become more visible. The peak at $2250 \mathrm{~cm}^{-1}$, absent in pure PMMA, is assigned to stretching vibrations of nitrile groups. The peaks at 1770 and $1670 \mathrm{~cm}^{-1}$ were assigned to the symmetric and asymmetric stretching vibrations of $\mathrm{C}=\mathrm{O}$, respectively [15]; the bands at $1445 \mathrm{~cm}^{-1}$ (PMMA) and $1405 \mathrm{~cm}^{-1}$ (CEPVA) can be attributed to the bending vibration of the $\mathrm{C}-\mathrm{H}$ bonds. All spectra showed the symmetric stretching vibrations of $\mathrm{C}-\mathrm{O}-\mathrm{C}$ at $1150 \mathrm{~cm}^{-1}$ for PMMA and at $1100 \mathrm{~cm}^{-1}$ for
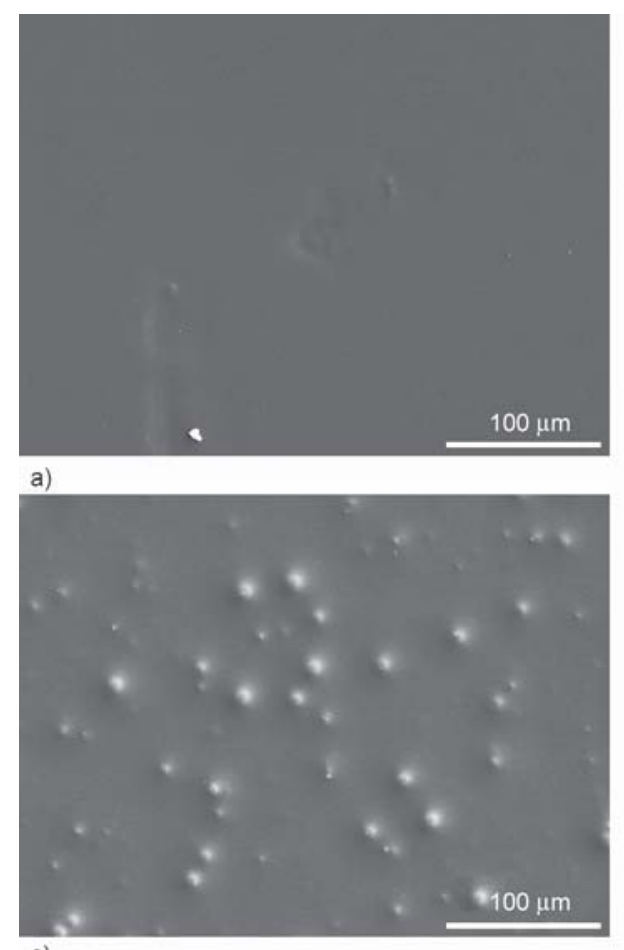

c)
CEPVA. There was no shift of the IR vibration peaks observed in the blend compared to the respective pure polymer, suggesting that there is almost no reciprocal interference between the functional groups of these two polymers in the blends in solid state. The only interaction could be seen from the change of the relative intensity between symmetric and asymmetric stretching peak of $\mathrm{C}=\mathrm{O}$, which could be attributed to an increased disorder in the PMMA chain arrangement.

The structures of the most relevant mixed polymer samples were observed via SEM microscopy. The pure polymers did not yield any significant information. The sample P-C 50-50 represented a totally separated biphasic system visible even with naked eye and it has been excluded from further analysis except for DSC. The sample P-C 10-90 has a homogeneous flat surface, same as the pure CEPVA (Figure 2a). At this concentration the PMMA is totally soluble in CEPVA. A similar situation has been found in the sample P-C 30-70 but small local defects could be observed due to an incipient phase separation (Figure 2b). In contrast, the sample P-C 70-30 shows a disordered blend structure with 5-10 $\mu \mathrm{m}$ spherical CEPVArich phase embedded into the PMMA-rich phase (Figure 2c). Such morphology makes this concentration useless for applications in organic electronics. The P-C 90-10 sample is also a blend with a rough

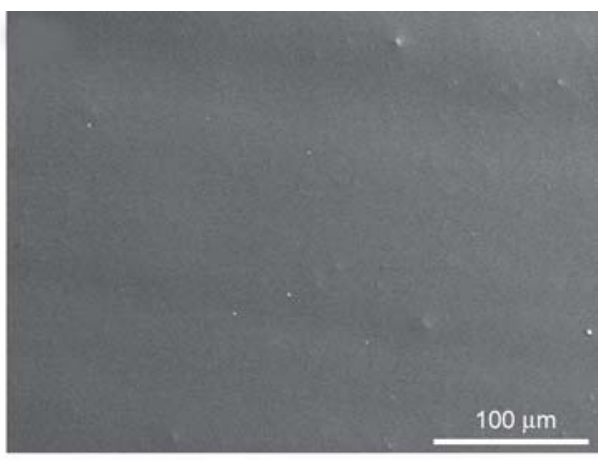

b)

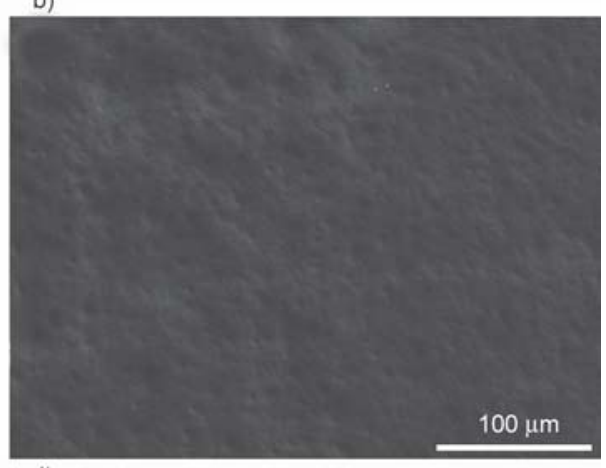

d)

Figure 2. Analysis of the top surface of the drop-cast polymer blend films: a) P-C 10-90; b) P-C 30-70; c) P-C 70-30; d) P-C 90-10 
surface but with a much more fine and homogeneous distribution of the CEPVA phase embedded in submicrometre scale spheres (Figure 2d).

DSC analyses show well defined $T_{\mathrm{g}}$ of CEPVA around $23^{\circ} \mathrm{C}$ and the $T_{\mathrm{g}}$ of PMMA at $108^{\circ} \mathrm{C}$. The experiments confirm the observation made in SEM, showing the absence of $T_{\mathrm{g}}$ typical for the pure PMMA in the samples P-C 10-90 and P-C 30-70, in which PMMA and CEPVA form a solid solution (Figure 3). Moreover, the $T_{\mathrm{g}}$ corresponding to the CEPVA polymer is clearly visible even at the CEPVA content of $10 \%$, in which the $T_{\mathrm{g}}$ is increased up to $31^{\circ} \mathrm{C}$. Even more intense is the effect of CEPVA on the $T_{\mathrm{g}}$ of PMMA, which increased from $108^{\circ} \mathrm{C}$ in pure PMMA to $120^{\circ} \mathrm{C}$ in the sample P-C $90-10$ having only $10 \%$ of CEPVA, and reaches the maximum value $T_{\mathrm{g}} \sim$ $125^{\circ} \mathrm{C}$ for the blends with the CEPVA content of $30 \%$. The increase of both $T_{\mathrm{g}}$ evidences the mutual interaction of polymers in the blends.

The frequency dependencies of the dielectric characteristics performed on PMMA-CEPVA blends in the range $10^{-2}-10^{7} \mathrm{~Hz}$ at room temperature show trends determined by the predominant polymer (Figure 4). The pure CEPVA polymer shows three regions in the frequency dependences with two characteristic relaxation bands, one at frequencies less than $10^{1} \mathrm{~Hz}$ and the second one at frequencies over $10^{5} \mathrm{~Hz}$, while the pure PMMA has a relaxation band centered at $10^{2} \mathrm{~Hz}$. As expected, the values of $\varepsilon^{\prime}$ increased with the addition of $10 \mathrm{wt} \%$ of CEPVA compared to the pure PMMA, since CEPVA itself has a higher $\varepsilon^{\prime}$ (see Figure 4a). Surprisingly, the blends have even higher permittivity compared to pure CEPVA,

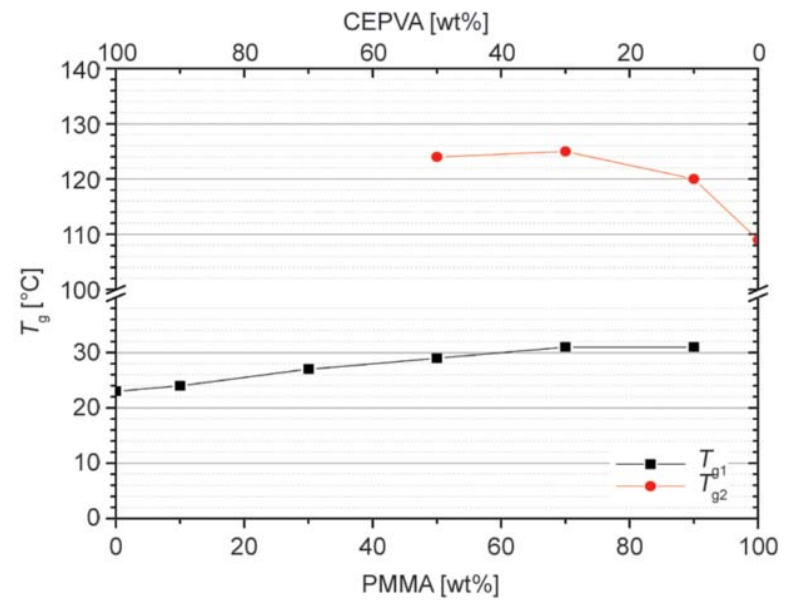

Figure 3. Summary of DSC analyses of PMMA-CEPVA polymer blends with various polymer compositions as shown for blends with 10 and $30 \mathrm{wt} \%$ PMMA, but the increase is not linear with the concentration. Since IR spectra do not show any significant interaction between PMMA and CEPVA functional groups in solid state at RT, this effect has been initially attributed to the impact of PMMA on the rearrangement of CEPVA chains during the evaporation of the solvent. At higher concentrations of PMMA the impact of PMMA on $\varepsilon^{\prime}$ of CEPVA saturates and the total permittivity of the blends decreases, following the lower $\varepsilon^{\prime}$ of PMMA. Comparing electrical conductivity
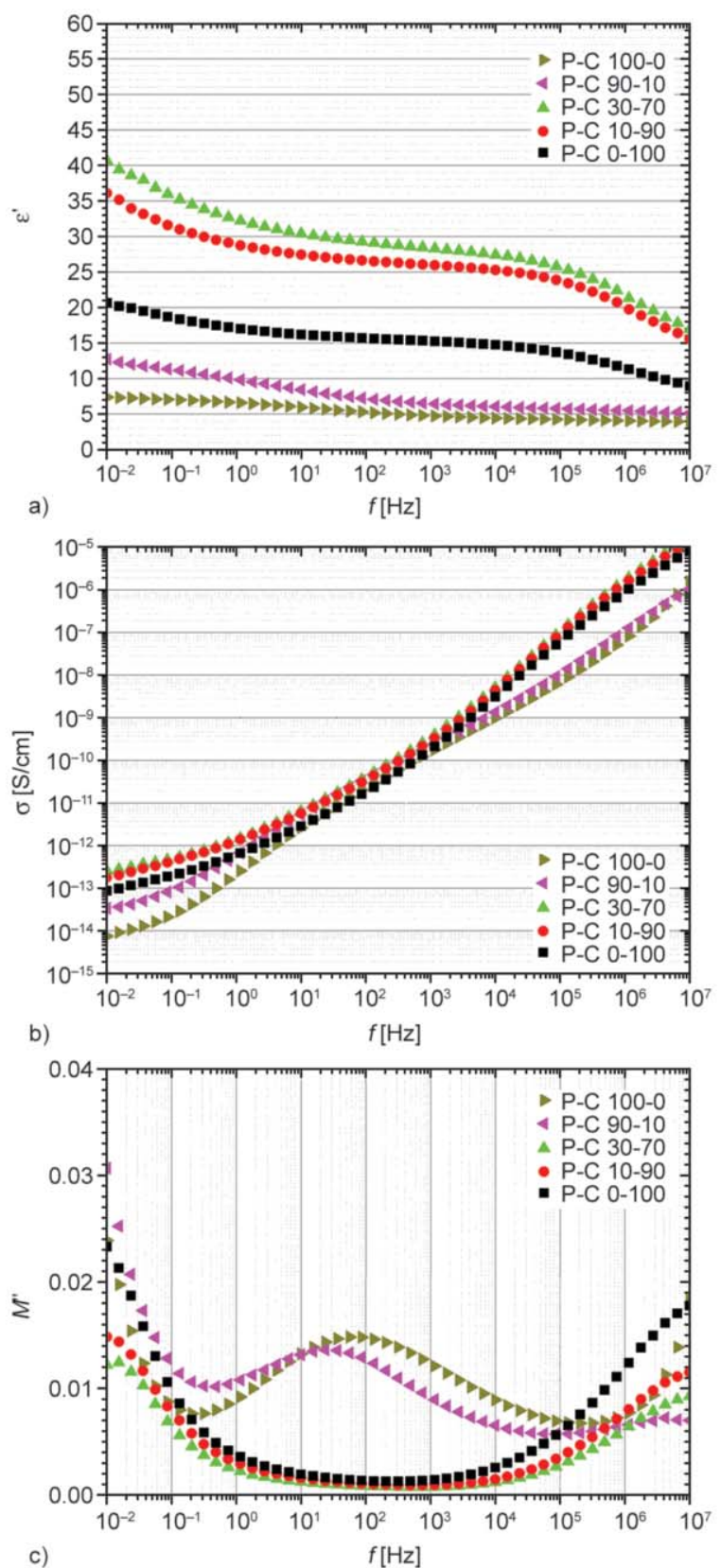

Figure 4. Dielectric properties of PMMA-CEPVA polymer blends samples with various compositions measured at $20^{\circ} \mathrm{C}$ : a) real part of permittivity; b) real part of conductivity; c) loss modulus 
$(\sigma)$ of the polymer blends with the pure PMMA polymer we also observed a slight increase (Figure $4 \mathrm{~b}$ ) caused probably by residua of ionic species, presence of which can be expected due to the polar nature of CEPVA polymer having good affinity to humidity and ionic impurities. Such impurities are difficult to remove completely without damaging the polymer. In order to evaluate the applicability of the blends in OFET structures we estimated the leakage current, which could occur in an OFET during the operating conditions. If we consider the measured low-frequency conductivity limit of the blend P-C 30-70, which has the highest dielectric constant and the highest conductivity, thickness of the dielectrics $500 \mathrm{~nm}$, achievable by printing technologies, and a maximum operating voltage of $5 \mathrm{~V}$, the leakage current would be about $25 \mathrm{nA} / \mathrm{cm}^{2}$, i.e. still negligible, without any effect on the functionality of the transistor in an electronic circuit [16].

Temperature influence on the dielectric properties of the studied system is shown in terms of $\varepsilon^{\prime}$ and $\varepsilon^{\prime \prime}$ in Figure 5. The main effect is connected with the $T_{\mathrm{g}}$,
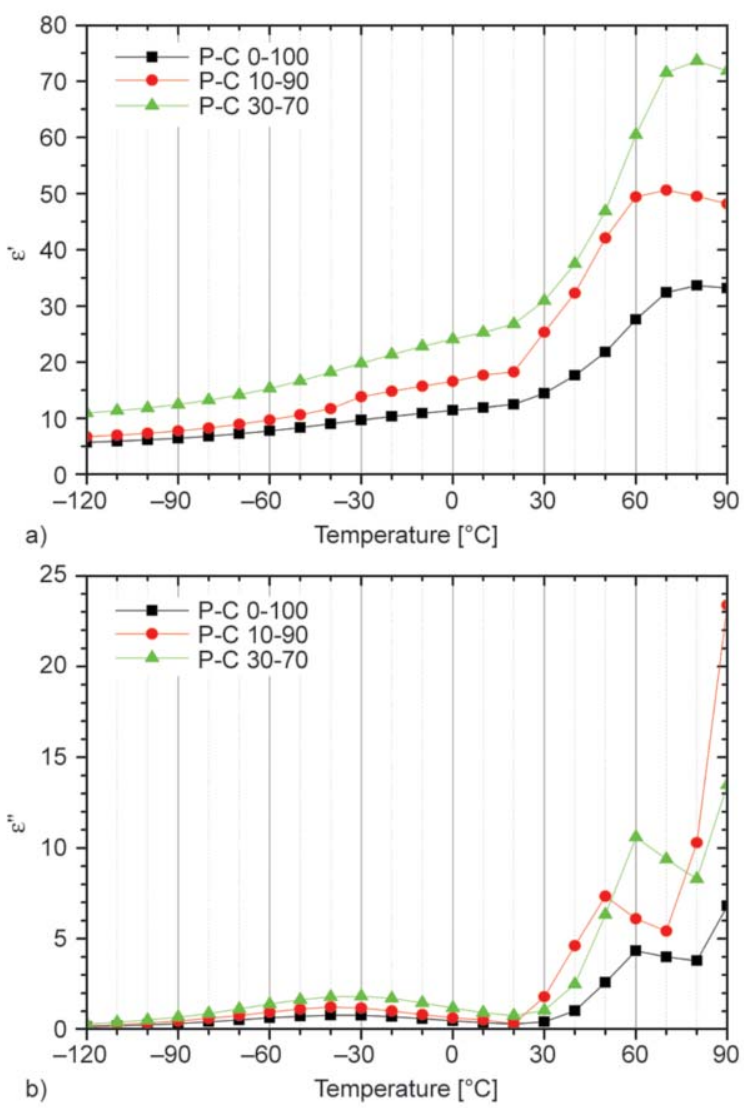

Figure 5. Temperature dependence of the real a) and imaginary b) part of the permittivity of PMMA-CEPVA polymer blends measured at frequency $1 \mathrm{kHz}$ for different compositions above which both the $\varepsilon^{\prime}$ and $\varepsilon^{\prime \prime}$ increase significantly, as is typical for polymers with high density of permanent dipoles. PMMA does not influence the trend but the absolute values of $\varepsilon^{\prime}$ and $\varepsilon^{\prime \prime}$, which both increase with its concentration. In all the samples $\varepsilon^{\prime \prime}$ shows a maximum related to the $\beta$-relaxation and a strong increase corresponding to the $\alpha$-relaxation at the highest temperatures, whereas $\varepsilon^{\prime}$ reaches a plateau or it even decreases. Unfortunately, at $T>90^{\circ} \mathrm{C}$ an electrical breakdown occurred in all prepared films under study.

In the Figure $4 \mathrm{c}$ the loss modulus $\left(M^{\prime \prime}\right)$ is plotted, which proves the relaxation phenomena at $20^{\circ} \mathrm{C}$ already observed in $\varepsilon^{\prime}$. To resolve the influence of the blend composition on these relaxations, a broadband spectroscopy has been performed in the temperature range $-120-100^{\circ} \mathrm{C}$ and frequency range $10^{-2}-10^{7} \mathrm{~Hz}$, and the activation energy $\left(E_{\mathrm{a}}\right)$ and the relaxation time $\left(\tau_{0}\right)$ of these relaxations were obtained. Plotting the logarithm of the frequency at which the maximum of $M^{\prime \prime}$ occurs as a function of the reciprocal temperature, the Arrhenius plots have been obtained, shown in Figure 6. According to the Vogel-Fulcher-Tammann-Hesse (VFTH) model $[17,18]$ the frequency $f_{\max }$ at which $M^{\prime \prime}$ reaches the maximum depends on temperature according to the Equation (1):

$\ln f_{\max }=\ln f_{0}-\frac{B}{T-T_{0}}$

where $\ln f_{0}$ is the intercept on the $y$-axis $(T \rightarrow \infty) . B$ is an optimized parameter for fitting the experimental data, corresponding to $T_{0}=0 \mathrm{~K}$ at the hindering barrier (Arrhenius case). For $T \rightarrow \infty$ the parameter $B$ assumes the value $E_{\mathrm{a}} / k$ with $E_{\mathrm{a}}$ being the activation energy and $k$ the Boltzmann constant. $T_{0}$ (called VogelFucher temperature) is a parameter corresponding mathematically to the vertical asymptote of the hyperbole and physically to the lowest temperature at which the relaxation can occur [19]. The results are summarized in Table 1.

The values of $T_{0}$ are not significantly influenced by the blend composition, although a slight decrease is observed for both the $\alpha$ and $\beta$ relaxations in the blends compared to pure polymers. It is of interest that the $T_{0}$ of the $\alpha$ relaxation, which should be related to the $T_{\mathrm{g}}$ of CEPVA follows a different trend it slightly decreases with increasing content of PMMA, whereas the increase in $T_{\mathrm{g}}$ was observed (see Figure 3) [7]. With increasing fraction of PMMA in the polymer blend, the $\tau_{0}$ of the CEPVA relaxation 


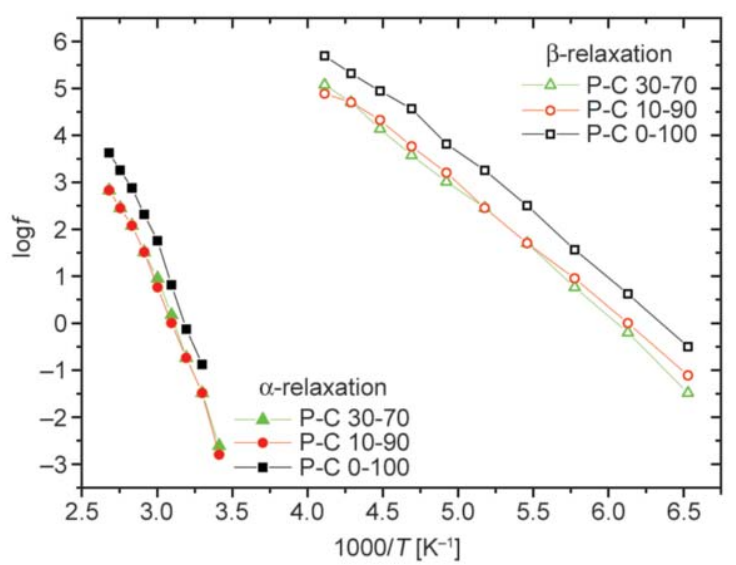

Figure 6. Arrhenius plot of frequencies of maximum of the modulus $M^{\prime \prime}$

increases and the activation energy calculated from the parameter $B$ of the VFTH model decreases markedly, suggesting an improved mobility of CEPVA side chains. These results were combined with the values of spin-spin relaxation times $(\tau)$ obtained by NMR spectroscopy (Table 2 ) for the neat CEPVA in DMF solution (P-C 0-100), and mixture of PMMA and CEPVA in composition 1-9 (P-C 10-90). It was observed that adding $10 \%$ of PMMA results in increasing $\tau$ values of hydroxyl and of methylene group adjacent to cyano group, which is an evidence of higher mobility in these groups [20]. Unfortunately the peak of the methylene adjacent to the etheric group overlaps the peaks of PMMA and consequently could not provide reliable data.

\section{Conclusions}

We have shown in this work that the dielectric constant of CEPVA polymer thin films can be further increased when blended with a suitable polymer like PMMA, even though the dielectric constant of the added polymer is lower. Blending also increases $T_{\mathrm{g}}$ : the blends having 10-30 wt $\%$ of PMMA showed an increase in $T_{\mathrm{g}}$ of the blend up to $29-30^{\circ} \mathrm{C}$ compared to $22{ }^{\circ} \mathrm{C}$ of the pure CEPVA. The dielectric constant
Table 2. Spin-spin relaxation time of CEPVA groups in $\mathrm{DMF}_{\mathrm{d} 7}$ solutions $(50 \mathrm{mg} / \mathrm{mL})$

\begin{tabular}{|l|c|c|c|}
\hline \multicolumn{1}{|c|}{ Sample } & $\begin{array}{c}\boldsymbol{\tau} \mathbf{\text { OH }} \\
{[\mathbf{s}]}\end{array}$ & $\begin{array}{c}\boldsymbol{\tau} \mathbf{C H}_{\mathbf{2}} \mathbf{C N} \\
{[\mathbf{s}]}\end{array}$ & $\begin{array}{c}\boldsymbol{\tau} \mathbf{\mathbf { O } - \mathbf { C H } _ { 2 }} \\
{[\mathbf{s}]}\end{array}$ \\
\hline CEPVA & 0.133 & 0.315 & 0.053 \\
\hline P-C 10-09 & 0.191 & 0.368 & - \\
\hline
\end{tabular}

increased from $\varepsilon^{\prime}=15$ (pure CEPVA) to $\varepsilon^{\prime}=27$ for the blend containing $30 \mathrm{wt} \%$ of PMMA. On the basis of the dielectric spectroscopy and NMR measurements we assigned the improvement of the dielectric constant to the impact of PMMA on the CEPVA side chain mobility and its relaxation phenomena. As seen from the NMR experiments, the hydrogen bonds between the hydroxyl and cyano groups of the CEPVA molecules in solutions are diminished in the presence of PMMA, CEPVA molecules become more mobile and they can achieve a more favorable arrangement during solvent evaporation. Moreover, in the solid phase the dielectric spectroscopy showed longer relaxation times and lower activation energies for CEPVA relaxations in presence of PMMA compared to the neat polymer. CEPVA films containing 10 to $30 \mathrm{wt} \%$ represent a good combination of morphological and dielectric properties, a good fit to ink-jet printing requirements and fulfils the needs of flexible organic electronic applications. Above this concentration, phase separation occurs, which markedly affects the morphology of the films. On the other hand, the blend containing only $10 \mathrm{wt} \%$ CEPVA (sample P-C 90-10) provides an interesting biphasic material with homogenously distributed domains and with higher $T_{\mathrm{g}}$ and increased $\varepsilon^{\prime}$ compared to the neat PMMA.

\section{Acknowledgements}

Supported by the Ministry of Education, Youth and Sports of CR within the National Sustainability Program I (NPU I), Project POLYMAT, LO1507. The authors also thank to Mgr. Ing. Rafał Konefał for performing the NMR measurements and Mr. Matouš Polauf for technical support.

Table 1. Relaxation parameters extrapolated from $M^{\prime \prime}$ measured by dielectric spectroscopy

\begin{tabular}{|c|c|c|c|c|c|}
\hline \multirow{2}{*}{ Relaxation } & Sample & $\log \boldsymbol{\tau}_{\mathbf{0}} \cdot \mathbf{1 0}^{-\mathbf{2}}$ & $\boldsymbol{B} \cdot \mathbf{1 0}^{-\mathbf{3}}$ & $\begin{array}{c}\boldsymbol{E}_{\mathbf{a}} \\
{[\mathbf{e V}]}\end{array}$ & $\begin{array}{c}\boldsymbol{T}_{\mathbf{0}} \\
{[\mathbf{K}]}\end{array}$ \\
\hline \multirow{3}{*}{$\alpha$} & P-C 0-100 & $-1.03 \pm 0.09$ & $2.1 \pm 0.5$ & $0.18 \pm 0.04$ & $2.2 \pm 0.1 \cdot 10^{2}$ \\
\cline { 2 - 6 } & P-C 10-90 & $-1.10 \pm 0.10$ & $1.5 \pm 0.4$ & $0.13 \pm 0.03$ & $1.8 \pm 0.2 \cdot 10^{2}$ \\
\cline { 2 - 6 } & P-C 30-70 & $-8.90 \pm 0.60$ & $1.1 \pm 0.2$ & $0.09 \pm 0.01$ & $2.0 \pm 0.1 \cdot 10^{2}$ \\
\hline \multirow{3}{*}{$\beta$} & P-C 0-100 & $-1.38 \pm 0.07$ & $3.3 \pm 0.5$ & $0.28 \pm 0.04$ & $4.9 \pm 0.9 \cdot 10^{1}$ \\
\cline { 2 - 6 } & P-C 10-90 & $-1.20 \pm 0.10$ & $1.5 \pm 0.4$ & $0.14 \pm 0.03$ & $4.2 \pm 0.6 \cdot 10^{1}$ \\
\cline { 2 - 6 } & P-C 30-70 & $-1.22 \pm 0.06$ & $1.6 \pm 0.2$ & $0.14 \pm 0.01$ & $4.4 \pm 0.8 \cdot 10^{1}$ \\
\hline
\end{tabular}




\section{References}

[1] Garnier F., Hajlaoui R., Yassar A., Srivastava P.: Allpolymer field-effect transistor realized by printing techniques. Science, 265, 1684-1686 (1994). https://doi.org/10.1126/science.265.5179.1684

[2] Holliday S., Donaghey J. E., McCulloch I.: Advances in charge carrier mobilities of semiconducting polymers used in organic transistors. Chemistry of Materials, 26, 647-663 (2014). https://doi.org/10.1021/cm402421p

[3] Lee K. H., Lee K., Oh M. S., Choi J-M., Im S., Jang S., Kim E.: Flexible high mobility pentacene transistor with high- $k$ /low $k$ double polymer dielectric layer operating at -5 V. Organic Electronics, 10, 194-198. https://doi.org/10.1016/j.orgel.2008.09.005

[4] Kalika D. S.: Dielectric spectroscopy of crystalline polymers and blends. in 'Handbook of low and high dielectric constant materials and their applications' (ed.: Nalwa H. S.) Academic Press, Burlington, 275-327 (1999). https://doi.org/10.1016/B978-012513905-2/50009-1

[5] Li R., Zhang L., Shi Z. L., Pei J. Z.: Effects of coupling agents on the structure and electrical properties of PZTpoly (vinylidene fluoride) composites. Applied Sciences, 6, 282/1-282/7 (2016). https://doi.org/10.3390/app6100282

[6] Cheng X., Caironi M., Noh Y-Y., Wang J., Newman C., Yan H., Facchetti A., Sirringhaus H.: Air stable crosslinked cytop ultrathin gate dielectric for high yield lowvoltage top-gate organic field-effect transistors. Chemistry of Materials, 22, 1559-1566 (2010). https://doi.org/10.1021/cm902929b

[7] Van de Leur R. H. M.: An extended analysis of the dielectric properties of poly[(2-cyanoethyl vinyl ether)co-(vinyl alcohol)]. Polymer, 35, 2691-2700 (1994). https://doi.org/10.1016/0032-3861(94)90294-1

[8] Myakin S. V., Korsakov V. G., Panova T. I., Sosnov E. A., Fomchenkova Y. C., Sychov M. M., Shilova O. A.: Effect of the modification of barium titanate on the permittivity of its composites with cyanoethyl ester of polyvinyl alcohol. Glass Physics and Chemistry, 37, 624-628 (2011).

https://doi.org/10.1134/s1087659611060125

[9] Borodzyulya V. F., Myakin S. V., Sudar' N. T., Sheiko N. B., Rodionov A. G., Sychov M. M.: Effect of conductivity on the dielectric characteristics of cyano-ethyl ester of poly(vinyl alcohol). Physics of the Solid State, 55, 1647-1650 (2013).

https://doi.org/10.1134/s1063783413080064

[10] Bäcklund T. G., Sandberg H. G. O., Österbacka R., Stubb H., Mäkelä T., Jussila S.: Towards all-polymer field-effect transistors with solution processable materials. Synthetic Metals, 148, 87-91 (2005).

https://doi.org/10.1016/j.synthmet.2004.08.033
[11] Paniagua S. A., Kim Y., Henry K., Kumar R., Perry J. W., Marder S. R.: Surface-initiated polymerization from barium titanate nanoparticles for hybrid dielectric capacitors. ACS Applied Materials \& Interfaces, 6, 3477 3482 (2014). https://doi.org/10.1021/am4056276

[12] Macutkevic J., Paddubskaya A., Kuzhir P., Banys J., Maksimenko S., Kuznetsov V. L., Mazov I. N., Krasnikov D. V.: Dielectric properties of polymer composites with carbon nanotubes of different diameters. Journal of Nanoscience and Nanotechnology, 14, 5430-5434 (2014). https://doi.org/10.1166/jnn.2014.8705

[13] Gross S., Camozzo D., Di Noto V., Armelao L., Tondello E.: PMMA: A key macromolecular component for dielectric low- $\kappa$ hybrid inorganic-organic polymer films. European Polymer Journal, 43, 673-696 (2007). https://doi.org/10.1016/j.eurpolymj.2006.12.012

[14] Farrar T. C., Becker E. D.: Pulse and fourier transform NMR. Academic Press, New York (1971).

[15] Li R., Wang C., Wang P., Pei J.: Preparation of a novel flow improver and its viscosity-reducing effect on bitumen. Fuel, 181, 935-941 (2016). https://doi.org/10.1016/j.fuel.2016.05.028

[16] Keum C-M., Bae J-H., Kim M-H., Choi W., Lee S-D.: Solution-processed low leakage organic field-effect transistors with self-pattern registration based on patterned dielectric barrier. Organic Electronics, 13, 778-783 (2005).

https://doi.org/10.1016/j.orgel.2012.02.003

[17] Fulcher G. S.: Analysis of recent measurements of the viscosity of glasses. Journal of the American Ceramic Society, 8, 339-355 (1925). https://doi.org/10.1111/j.1151-2916.1925.tb16731.x

[18] Tammann G., Hesse W.: Die Abhängigkeit der Viscosität von der Temperatur bie unterkühlten Flüssigkeiten. Zeitschrift für Anorganische und Allgemeine Chemie, 156, 245-257 (1926). https://doi.org/10.1002/zaac.19261560121

[19] Dyre J. C.: Colloquium: The glass transition and elastic models of glass-forming liquids. Reviews of Modern Physics, 78, 953-972 (2006).

https://doi.org/10.1103/RevModPhys.78.953

[20] Strachota B., Matějka L., Zhigunov A., Konefał R., Spěváček J., Dybal J., Puffr R.: Poly( $N$-isopropylacrylamide)-clay based hydrogels controlled by the initiating conditions: Evolution of structure and gel formation. Soft Matter, 11, 9291-9306 (2015).

https://doi.org/10.1039/c5sm01996f 